JP3I (Jurnal Pengukuran Psikologi dan Pendidikan Indonesia), 8(I), 2019, 13-24

DOl: http://dx.doi.org/I0.15408/jp3i.v8il.I2803

http://journal.uinjkt.ac.id/index.php/jp3i

\title{
Validasi Modul "Kelasku Menyatu Tanpa Batas" untuk Mengubah Sikap Guru terhadap Pendidikan Inklusif
}

\author{
Tia Inayatillah, Budi Andayani \\ Universitas Gajah Mada, Indonesia \\ inayatillah.tia@gmail.com
}

\begin{abstract}
The implementation of inclusive education in Yogyakarta has yet to reflect the granting of rights and equal access to education for students with disabilities. The misconception of inclusive term leads to negative attitudes of teachers then becomes the barriers of successful inclusive teaching. This research aims to validate "Kelasku Menyatu Tanpa Batas" module to change teacher's attitude toward inclusive education. This research will be done through a quasi experiment using the design named Untreated Control Group Design with Dependent pre-test and post-test samples. The subjects are I8 teachers of primary schools in Yogyakarta which will be divided into 2 groups, the experiment group and the control group. Analysis will be held through Man-Withney U Test statistical test. The finding $(Z=-3,054 ; p<0,0 I)$ shows that "Kelasku Menyatu Tanpa Batas" training could change teacher's attitude towards inclusive education.
\end{abstract}

Keywords: inclusive education; barrier; teacher; students with disabilities

\begin{abstract}
Abstrak
Implementasi pendidikan inklusif di Kota Yogyakarta masih belum mencerminkan pemberian hak dan akses pendidikan yang sesuai dengan siswa yang memiliki disabilitas. Miskonsepsi terhadap prinsip inklusi ditemukan menjadi penghambat kesuksesan inklusi dan penyebab berkembangnya belief yang membentuk sikap negatif guru terhadap pendidikan inklusif. Penelitian ini bertujuan menguji validitas modul "Kelasku Menyatu Tanpa Batas" dalam mengubah sikap guru terhadap pendidikan inklusif. Penelitian dilakukan melalui eksperimen kuasi menggunakan desain Untreated Control Group Design with Dependent pre-test and post-test samples. Subjek adalah I8 orang guru SD di Kota Yogyakarta yang terbagi kedalam dua kelompok, yaitu kelompok eksperimen dan kelompok kontrol. Analisis dilakukan melalui uji statistika Man-Withney $U$ Test $(\mathrm{Z}=-3,054 ; \mathrm{p}<0,0 \mathrm{I})$ menunjukkan bahwa terdapat perbedaan yang signifikan antara kelompok kontrol dan eksperimen setelah mendapat perlakuan. Dari hasil tersebut dapat disimpulkan bahwa pelatihan "Kelasku Menyatu Tanpa Batas" teruji valid dapat mengubah sikap guru terhadap pendidikan inklusif.
\end{abstract}

Kata kunci: pendidikan inklusif; guru; siswa dengan disabilitas 


\section{Pendahuluan}

Diskriminasi sebagai bentuk perilaku yang mendiskreditkan fungsi dan nilai individu dalam tatanan sosial bermasyarakat masih menjadi kajian penting dalam berbagai penelitian. Banyak kerugian yang dialami oleh individu (atau kelompok) akibat adanya diskriminasi ini, diantaranya adalah pandang negatif dari lingkungan, label "tidak berguna", "tidak berharga”, dan "beban" dalam tatanan sosial bermasyarakat, yang mengakibatkan mereka tidak diberi kesempatan untuk mendapatkan haknya sebagaimana individu lain (Crisp, 20I0).

Diskriminasi terjadi di berbagai ranah kehidupan, tidak terkecuali di lembaga pendidikan, yaitu sekolah. Diskriminasi yang umum terjadi di sekolah, baik disadari atau tidak disadari, adalah diskriminasi yang ditujukan bagi individu dengan disabilitas, yaitu individu dengan kondisi keterbatasan tertentu yang menghambatnya untuk dapat berfungsi secara adaptif di lingkungan sosial. Siswa dengan disabilitas (atau yang lebih dikenal di Indonesia dengan istilah ABK (Anak Berkebutuhan Khusus)) seringkali dibatasi aktivitasnya di sekolah, tidak dilibatkan dalam berbagai kegiatan, sehingga mereka merasa terasing di kelas. (Booth \& Ainscow, 20 I I; Connor \& Ferri, 2007).

Menanggapi fenomena di atas, maka dirumuskanlah pergerakan pengentasan diskriminasi yang dinamakan program pendidikan inklusif (Lindsay, 2007). Program ini merupakan program pendidikan yang berupaya memfasilitasi kesetarakan hak dan aksesibilitas pendidikan melalui pengintegrasian siswa ABK dengan siswa lainnya di lingkungan yang sama (Falvey \& Givner, 2005). Pendidikan inklusif diharapkan dapat memberikan pembelajaran yang positif bagi individu dalam menanggapi "perbedaan", karena pendidikan inklusif memungkinkan setiap individu memandang "perbedaan” sebagai suatu keunikan pribadi yang perlu dihargai, sebagaimana dirinya yang juga "unik" dan menginginkan penghargaan orang lain atas keunikannya (Booth \& Ainscow, 201 I).

Salah satu daerah di DIY yang memiliki komitmen yang kuat dalam memberikan layanan pendidikan pada siswa ABK adalah Kota Yogyakarta. Pemerintah Kota Yogyakarta bahkan telah mengimplementasikan pendidikan inklusif sejak disahkannya Peraturan Wali Kota No. 47 tahun 2008 tentang Penyelenggaraan Pendidikan Inklusif di kota Yogyakarta. Peraturan ini bahkan muncul satu tahun lebih awal dibanding Peraturan Menteri Pendidikan Nasional (Permendiknas) yang disahkan pada tahun 2009. Hal ini membuat Kota Yogyakarta kerap dijuluki sebagai "Kota Inklusi” (Antara News, 20I6). Namun demikian, meski telah menyelenggarakan program pendidikan inklusif telah berjalan kurang lebih sepuluh tahun, ternyata penyelenggaraannya ini masih belum menunjukkan hasil yang memuaskan. Kepala Manajemen Pendidikan Dasar Dinas Pendidikan Kota Yogyakarta menyatakan bahwa dalam prosesnya, banyak hal yang membuat pendidikan inklusif di Kota Yogyakarta belum terimplementasi secara efektif. Hal ini terutama terjadi pada jenjang Sekolah Dasar (SD) yang memiliki persentase siswa ABK paling banyak.

Evaluasi implementasi pendidikan inklusif tidak dilihat dari seberapa banyak jumlah siswa ABK dalam satu sekolah, melainkan dari seberapa banyak praktik penyelenggaraan pendidikan yang tercermin dari aktualisasi nilai inklusi (Booth, 20I I; Grenier, 20I0; Moen, 2008). "Inklusi” berarti mengikutsertakan setiap individu yang beragam ke dalam suatu aktivitas bersama atas dasar prinsip kesamaan hak, kepercayaan, keberanian, dan rasa kasih sayang, bukan hanya memberikan kesempatan bagi siswa disabilitas untuk merasakan duduk di ruangan yang sama, sementara posisi dan status sosial masih tetap dianggap tidak setara (Booth \& Ainscow, 20II). Beberapa peneliti yang melakukan evaluasi terhadap proses implementasi inklusi yang dilakukan oleh SPPI (Sekolah Penyelenggara Pendidikan Inklusif) di Kota Yogyakarta memberikan kesimpulan bahwa sekolah "belum siap" dalam menjalankan pendidikan inklusif. Terdapat beberapa faktor yang masih menghambat dan perlu diupayakan agar sekolah siap untuk mengimplementasikan pendidikan inklusif, salah satu yang utama adalah sikap guru terhadap pendidikan inklusif (Hanjarwati \& Aminah, 20I4; Ishartiwi, 2010; Lubis, 2016; Tarnoto, 2014). 
Hasil observasi impelementasi inklusi di Kota Yogyakarta masih belum mencerminkan implementasi prinsip inklusi yang efektif di kelas inklusif, karena pembelajaran di kelas berorientasi pada nilai akademik, tidak adanya asesmen yang kontinu dan menyeluruh terhadap proses pembelajaran di kelas, dan tidak diberlakukannya kurikulum berdiferensiasi sesuai dengan kemampuan siswa. Kesalahan umum yang terjadi pada praktik pendidikan inklusif adalah adanya keharusan bagi siswa ABK untuk mengubah diri atau menyesuaikan diri agar sesuai dengan kurikulum reguler, yang mana hal ini lebih menunjukkan proses asimilasi dibandingkan inklusi. Padahal, fokus pendidikan inklusif pelayanan yang dapat memberikan akses bagi semua siswa sehingga dapat berpartisipasi secara penuh dalam proses pembelajaran di kelas (Booth, 20II; Jordan, Glenn, \& McGhie-Richmond, 20I0; Moen, 2008). Oleh karena itu, perlu diselidiki penyebab berkembangnya praktik pengajaran yang tidak sesuai dengan prinsip inklusi ini (Loja, Costa, Hugher, \& Menezes, 2013).

Hasil temuan berdasarkan studi pendahuluan di atas menggambarkan adanya pandangan negatif guru SD di Kota Yogyakarta terhadap pendidikan inklusif yang menyebabkan praktik inklusi tidak optimal. Serangkaian penelitian yang dilakukan di Kanada selama sepuluh tahun terakhir terkait praktik pengajaran inklusif yang efektif menemukan bahwa faktor sikap merupakan penentu kesuksesan implementasi inklusif (Jordan, Schwartz, \& McGhie-Richmond, 2009). Sebagai salah satu determinan perilaku, sikap diartikan sebagai kecenderungan individu untuk berespon terhadap suatu objek (dapat berupa benda, orang, institusi, kejadian, atau aspek lainnya yang ada pada dunia individu) sesuai dengan hasil evaluasinya terhadap objek tertentu (Fishbein \& Ajzen, 1975). Sikap dapat menunjukkan seberapa besar kecenderungan seseorang untuk melakukan tindakan yang sesuai dengan objek sikapnya. Oleh karena itu, sikap positif terhadap pendidikan inklusif akan menunjukkan kecenderungan kuat dari guru untuk menerima dan mengimplementasikan pendidikan inklusif di sekolah. Sebaiknya, sikap negatif terhadap pendidikan inklusif menunjukkan kecenderungan untuk menolak implementasi pendidikan inklusif di sekolah (Savage \& Erten, 2015).

Sikap memiliki tiga komponen yang saling berinteraksi di dalamnya, yaitu komponen kognitif, afektif, dan perilaku (konatif). Lebih lanjut diungkapkan oleh Forlin, Eagle, Loreman, \& Sharma (20II) bahwa terdapat tiga dimensi yang dapat mengungkap sikap guru terhadap pendidikan inklusif, yaitu (I) evaluasi afektif guru saat berinteraksi dengan siswa yang mengalami disabilitas (sentiment); (2) evaluasi kognitif guru terhadap penggabungan siswa disabilitas di kelas reguler (attitude); dan (3) evaluasi guru terhadap konsekuensi dari implementasi pendidikan inklusif di kelas reguler (concern).

Berbagai penelitian menunjukan bahwa guru yang berasal dari sekolah reguler cenderung menunjukan sikap negatif terhadap program pendidikan inklusif akibat adanya penggabungan siswa disabilitas dan siswa reguler di dalamnya (Barr \& Brachita, 20I5; deBoer, Pijl, \& Minnaert, 20II; Kurniawati, deBoer, Minnaert, \& Mangunsong, 20I4; Woolfson \& Brady, 2009;). Sikap negatif terhadap pendidikan inklusif dibentuk oleh pandangan negatifnya terhadap program inklusi dengan siswa ABK berada di kelasnya, dimana guru yang mengevaluasi proses pengajaran di kelas inklusif secara negatif cenderung untuk menolak kehadiran siswa ABK di kelasnya dan tidak mengupayakan berbagai cara untuk mengembangkan diri dalam mengajar, begitu pun sebaliknya (Avradimis \& Kalyva, 2007). Hambatan dalam mensukseskan inklusi terletak pada belief bahwa menggabungkan siswa ABK ke dalam kelas reguler mustahil dapat berjalan efektif dan belief bahwa sebaiknya siswa disabilitas disekolahkan di sekolah khusus atau sekolah luar biasa (Sharma, 20II).

Albarrin dan Mcnatt (2005) menyatakan bahwa upaya untuk mengubah sikap dapat dilakukan melalui pelatihan yang melibatkan partisipasi aktif peserta yang disertai komunikasi persuasif. Program pelatihan merupakan faktor penting dalam membentuk sikap positif guru terhadap pendidikan inklusi (Baglieri, 2008; Beckett, 2009; Dukmak, 2013; Baker-Ericzén, Kurniawati, deBoer, Minnaert dan Mangunsong (2016); Muggenborg, \& Shea, 2009; deBoer, Pijl, \& Minnaert, 201I). Penelitian yang dilakukan oleh Anderson, Klassen, dan Georgiou (2007) terhadap 340 responden guru di Australia pun menunjukkan bahwa kebutuhan utama guru yang perlu diakomodasi oleh psikolog pendidikan adalah adanya pelatihan pengembangan kemampuan guru yang bertujuan untuk dapat menerima program inklusi ini dengan baik. 
Upaya untuk mengubah sikap guru terhadap pendidikan inklusif telah beberapa kali dilakukan oleh pemerintah maupun para peneliti di Kota Yogyakarta, salah satunya adalah penelitian yang dilakukan oleh Haifani (20II) kepada guru SD di Yogyakarta. Hasil penelitian menunjukkan bahwa program pelatihan berisi penjelasan mengenai konsep inklusi, siswa ABK, dan strategi penanganan siswa ABK dapat meningkatkan pengetahuan dan sikap guru terhadap siswa ABK. Namun demikian, perubahan sikap tidak terlalu signifikan dikarenakan beberapa hal, diantaranya adalah (I) materi pelatihan tidak menyasar esensi dari inklusi; dan (2) pelatihan kurang dapat melibatkan subjek untuk berpartisipasi aktif dalam mengubah belief yang dimilikinya mengenai inklusi dan siswa dengan disabilitas.

Sharma (20I I) menjelaskan adanya kekeliruan dalam desain pelatihan pengubahan sikap yang selama ini banyak dilakukan di wilayah Asia. Terdapat beberapa hal yang dicermati akan mempengaruhi efektivitas dari pelatihan, yaitu (I) pelatihan terlalu banyak berisi aturan-aturan mengenai inklusi tanpa menekankan konsep terkait "apa itu inklusi” sehingga banyak muncul miskonsepsi; (2) pelatihan terlalu fokus pada pemberian informasi mengenai "bagaimana menjalankan inklusi”, padahal untuk dapat mengubah sikap, yang dibutuhkan adalah informasi mengenai "mengapa inklusi"; dan (3) pelatihan banyak mengajarkan cara mengidentifikasi siswa ABK kedalam berbagai jenis ke-ABK-an, padahal hal ini akan berdampak pada pelabelan siswa kedalam kategori tertentu dan membuat guru merasa siswa tersebut bukan menjadi tanggung jawabnya.

Berdasarkan penjabaran di atas, maka penelitian ini bertujuan untuk menyusun suatu modul pelatihan yang dapat secara efektif mengubah sikap guru terhadap kegiatan mengajar di kelas inklusif melalui program "Kelasku Menyatu Tanpa Batas". Dalam penyusunan program, peneliti mempertimbangkan karakteristik guru sebagai pembelajar dewasa (adult learner) yang memiliki karakteristik khusus dalam hal konsep diri, pengalaman, kesiapan belajar, dan orientasi belajar (Mezirow, 1997). Karakteristik ini mensyaratkan adanya perbedaan dalam situasi belajar agar pembelajar bersedia menerima informasi yang diberikan, diantaranya adalah proses pembelajaran perlu memandangnya sebagai seseorang yang dapat berpikir secara kritis mengenai berbagai pengalaman yang dimilikinya.

Guru bukanlah orang yang awam akan pendidikan inklusif. Dalam hal ini, guru telah memiliki pengalaman mengajar yang lama dan belief-nya terhadap pendidikan inklusif sudah cukup kuat berdasarkan pengalamannya. Pengalaman yang dimilikinya ini telah membentuk suatu konsep mengenai inklusi namun belum konsep yang dimiliki belum terintegrasi dengan baik. Oleh karena itu pelatihan perlu disusun agar dapat memberikan informasi yang baru dan bermakna bagi guru, namun tetap menghargai pengalaman yang dimiliki guru sebelumnya. Dalam hal ini, pendekatan transformative learning oleh Mezirow (1997) ditemukan sesuai untuk menjadi landasan modul pelatihan dalam mengubah sikap pada pembelajar dewasa.

Menurut Mezirow (1997), proses belajar transformatif merupakan proses pembangunan makna baru terhadap pengalaman diri berdasarkan interpretasinya terhadap pengalaman sebelumnya, guna memandu tindakan-tindakan yang akan datang. Kegiatan pokok dari pembelajaran transformatif terletak pada refleksi kritis seseorang terhadap asumsi yang dimilikinya. Pembelajaran transformatif ini dapat digunakan sebagai pendekatan untuk mengubah sikap karena hal yang bisa diubah dari diri individu dalam pembelajaran transformatif pada dasarnya dapat berkenaan dengan berbagai aspek kehidupan yang mendasar, seperti pengubahan persepsi, pandangan, asumsi-asumsi, sikap, perasaan, kesadaran, bahkan keyakinan individu (Cranton \& King, 2003). Beragam metode belajar dapat dipakai untuk menunjang proses ini, diantaranya adalah action plan, kegiatan reflksi, studi kasus, evaluasi kurikulum, dan diskusi kelompok (Taylor, 2007). Apabila pembelajaran ini dapat diaplikasikan kedalam kegiatan pelatihan, maka kegiatan pelatihan tersebut memiliki peluang untuk tampil sebagai kegiatan yang cocok dan sangat berguna bagi pembelajar dewasa (Cranton \& King, 2003).

Russell \& Johanningsmeier (I98I) mengenalkan sebuah model konstruksi modul dan menyatakan bahwa modul merupakan sebuah paket instruksional yang berisi langkah-langkah yang dapat membantu individu memahami dan menguasai suatu materi atau kompetensi tertentu. Terdapat beberapa langkah yang dilakukan 
dalam penyusunan modul yaitu: (I) memahami subjek yang menjadi target modul; (2) memahami tujuan modul; (3) memiliki alat ukur untuk mengukur pencapaian, (4) uji coba pada subjek terbatas; dan (4) validasi modul.

Pelatihan guru yang berpusat pada kegiatan refleksi terhadap pemahamannya mengenai inklusi memberikan dampak yang lebih positif terhadap sikap guru terhadap pendidikan inklusif dibandingkan pelatihan yang terlalu banyak mengajarkan berbagai macam skill (Pijl, 20I I; Sharma, 20I2). Oleh karena itu modul pelatihan "Kelasku Menyatu Tanpa Batas" dikembangkan untuk mengubah sikap negatif guru dalam mengajar di kelas inklusif melalui proses refleksi kritis. Pelatihan diharapkan akan dapat membentuk belief positif guru terhadap inklusi sehingga sikapnya terhadap pendidikan inklusif akan menjadi positif. Program ini disusun berdasarkan modul Haifani (20I I) yang dimodifikasi berdasarkan hasil penelitian dari Pijl (20I0) \& Sharma (20I I).

Melalui model konstruksi modul Russell \& Johanningsmeier (I98I), validasi modul "Kelasku Menyatu Tanpa Batas" akan dilakukan guna mengetahui apakah modul dapat teruji secara valid untuk mengubah sikap negatif guru dalam mengajar di kelas inklusif melalui proses refleksi kritis. Pelatihan diharapkan akan dapat membentuk belief positif guru terhadap inklusi sehingga sikapnya terhadap pendidikan inklusif akan menjadi positif. Program ini disusun berdasarkan modul Haifani (20II) yang dimodifikasi berdasarkan hasil penelitian dari Pijl (20I0) \& Sharma (20II).

Hipotesis dalam penelitian ini adalah pelatihan "Kelasku Menyatu Tanpa Batas" dapat mengubah sikap guru terhadap pendidikan inklusif. Kelompok subjek yang mendapatkan perlakuan berupa program "Kelasku Menyatu Tanpa Batas" memiliki skor sikap yang lebih tinggi dibanding kelompok subjek yang tidak mendapat perlakuan. Dengan diselenggarakannya pelatihan ini, guru diharapkan dapat menerima dan memfasilitasi siswa ABK di kelasnya sesuai dengan prinsip pendidikan inklusif. Berdasarkan tujuan tersebut, maka disusunlah pelatihan dengan 6 sesi didalamnya, yaitu: (I) Pengantar; (2) Apa itu Inklusi?; (3) Mengapa harus inklusi?; (4) Siapakah ABK itu?; (5) Bagaimana proses belajar di kelas inklusif?; dan (6) Penutup.

\section{Metode}

\section{Variabel Penelitian}

Variabel tergantung dalam penelitian ini adalah sikap guru terhadap pendidikan inklusif. Sementara itu, Variabel bebas dalam penelitian ini adalah pelatihan "Kelasku Menyatu Tanpa Batas". Pelatihan "Kelasku Menyatu Tanpa Batas" adalah instrumen pelatihan yang berisi serangkaian kegiatan refleksi dan pemberian informasi kepada subjek penelitian terkait pendidikan inklusif yang ditunjang dengan berbagai media melalui pendekatan transformative learning.

\section{Subjek Penelitian}

Subjek penelitian dipilih melalui teknik purposive sampling berdasarkan kriteria tertentu. Subjek penelitian adalah guru SD di Kota Yogyakarta yang akan dibagi secara acak ke dalam kelompok eksperimen dan kelompok kontrol. Kriteria partisipan yaitu: (I) memiliki latar belakang pendidikan umum, bukan berasal dari jurusan Pendidikan Luar Biasa (PLB); (2) memiliki pengalaman mengajar minimal 2 tahun; (3) memiliki pengalaman mengajar siswa ABK di kelas; dan (4) memiliki skor sikap yang berada pada kategori sedang.

\section{Desain Eksperimen dan Analisis Data}

Desain eksperimen kuasi pada penelitian ini adalah untreated control group design with pre-test and post test. Desain tersebut merupakan rancangan umum diterapkan dalam penelitian sosial. Penelitian ini terdiri dari kelompok eksperimen dan kelompok kontrol (Shadish, Cook, \& Campbell, 2002). Sementara itu, analisis data hasil uji empiris dilakukan secara kuantitatif dengan uji statistika non parametric Mann Whitney U Test dan Wilcoxon Signed Rank. Analisa ini digunakan untuk membandingkan hasil dua kelompok data yaitu pretest dan postest SSGPI dan TPG pada kelompok eksperimen maupun hasil pretest dan postest SSGPI pada kelompok kontrol. 


\section{Alat Ukur}

Instrumen pengukuran dalam penelitian ini adalah Skala Sikap Guru terhadap Pendidikan Inklusif (SSGPI). Sikap guru terhadap pendidikan inklusif akan diukur melalui skala sikap yang dimodifikasi dari SACIE-R (Sentiment, Attitude, Concern, about Inclusive Education-Revised) yang dikonstruksikan oleh Forlin, dkk. (20II). Skala ini digunakan untuk mengukur sikap melalui 3 konstrak yang diturunkan dari teori sikap berdasarkan skema triadic component, yaitu (I) sentiment, merupakan komponen afektif dari sikap yang merujuk pada evaluasi perasaan seseorang saat berinteraksi dengan penyandang disabilitas.; (2) attitude, merupakan komponen kognitif dari sikap yang merujuk pada evaluasi terhadap pandangan, opini, ide, kepercayaan terkait isyu penggabungan siswa ABK di kelas reguler; dan (3) concern, merupakan komponen perilaku (konatif) dari sikap yang merujuk pada evaluasi seseorang terhadap dampak dari perilaku mengajar di kelas inklusif. Setelah dilakukan modifikasi alat ukur, didapat 20 aitem skala yang telah diujicobakan (penambahan 5 aitem dari skala SACIE-R) dengan koefisien reliabilitas sebesar 0,885, yang berarti bahwa skala ini dapat mewakili konstruk sikap yang ingin diteliti.

\section{Instrumen Pelatihan}

Instrumen yang digunakan dalam melaksanakan pelatihan adalah modul pelatihan "Kelasku Menyatu Tanpa Batas" yang akan digunakan pada guru SD yang mengajar di kelas inklusif. Pemberian nama "Kelasku Menyatu Tanpa Batas" digunakan oleh peneliti mengacu pada cita-cita terbentuknya pendidikan inklusif, yaitu pendidikan yang dapat mengakomodasi kebutuhan setiap siswa tanpa terkecuali dengan meminimalisir batasan-batasan yang ada di dalamnya. Pendekatan yang digunakan dalam pelatihan ini adalah pendekatan transformative learning, dimana setiap peserta akan bekerja secara aktif untuk melakukan aktivitas tertentu, mengolah dan memaknai kembali pengalaman mengajar kelas inklusif yang dimilikinya menjadi asumsi dan belief baru yang lebih positif melalui bantuan dari fasilitator. Metode yang digunakan adalah kegiatan refleksi, diskusi kelompok, studi kasus, dan action plan.

Sesi I "Pengantar" merupakan proses awal pembelajaran transformatif dimana peserta diberikan contoh situasi yang kontradiktif antara kondisi yang diharapkan pemerintah terkait pendidikan inklusif dengan kenyataan praktik inklusi di lapangan. Peserta selanjutnya diajak berdiskusi untuk menyepakati tujuan dari pelatihan melalui pertanyaan reflektif "Apakah inklusi yang kita yakini saat ini sudah tepat?”.

Sesi 2 “Apa itu Inklusi?" merefleksikan keyakinan peserta terhadap pendidikan inklusif “Apakah pemahaman saya tentang inklusi sudah tepat?”. Melalui kegiatan diskusi terhadap (I) nilai inklusi; (2) prinsip inklusi; dan (3) praktik eksklusi, studi kasus, dan kegiatan refleksi pengalaman mengajar sebelumnya, peserta diajak untuk membangun makna baru mengenai inklusi yang lebih tepat. Sesi ini diakhiri dengan penyimpulan terhadap pelaksanaan pendidikan inklusif di sekolah masing-masing, meliputi hal-hal yang sudah tepat maupun hal yang masih keliru dalam proses pelaksanaan inklusi di kelasnya yang perlu untuk diubah.

Sesi 3 "Mengapa harus Inklusi?" merefleksikan pengalaman guru selama mengajar di kelas inklusif dengan membandingkan manfaatnya dibandingkan pengajaran di SLB. Refleksi terhadap manfaat ini akan dilakukan melalui proses diskusi berdasarkan 3 sudut pandang, yaitu siswa reguler, siswa ABK, dan guru. Melalui kegiatan refleksi dan diskusi, peserta akan merefleksikan jawaban mengenai pertanyaan "Mengapa harus inklusi? Mengapa siswa ABK harus belajar di kelas reguler?".

Sesi 4 "Siapakah ABK itu?" merefleksikan stigma yang dibentuk masyarakat mengenai ABK dan bagaimana penolakan guru terhadap kehadiran ABK di kelasnya. Melalui kegiatan diskusi, penayangan video, dan kegiatan refleksi dilakukan setelah melihat video mengenai $A B K$ peserta diajak untuk membangun pemaknaan baru terhadap konsep $A B K$, bagaimana peran guru dalam menghadapi ABK, dan bagaimana cara memfasilitasi ABK di kelas. Proses refleksi diakhiri dengan refleksi terkait pengalaman keberhasilan guru dalam menangani ABK untuk mengubah pandangan bahwa "ABK tidak bisa diajar" dengan bukti bahwa guru pernah berhasil mengatasinya. 
Sesi 5 "Bagaimana Proses Pembelajaran di Kelas Inklusif?" merefleksikan perbedaan esensial antara proses pembelajaran di kelas inklusif dibandingkan di kelas reguler. Melalui kegiatan refleksi, peserta dapat membangun pemahaman bahwa belajar merupakan suatu bentuk komunikasi, maka peserta perlu memahami karakteristik siswa sebelum menjalankan proses belajar.

Sesi 6 "Penutup" bertujuan untuk mengelaborasi belief baru peserta mengenai inklusi setelah proses transformasi dilakukan sepanjang pelatihan. Melalui FGD, peserta akan merefleksikan perubahan pandangan apa yang dimilikinya pada sebelum dan sesudah pelatihan. Sementara itu, melalui proses diskusi peserta akan dapat merefleksikan pertanyaan akhir untuk mengecek pemahaman general guru terhadap pendidikan inklusif, yaitu melalui pertanyaan "Apa manfaat dari mengajar di kelas inklusif?".

\section{Hasil dan Pembahasan}

\section{Hasil}

Berdasarkan hasil pengujian statistik menggunakan analisis statistik non parametrik Mann Withney UTest, didapatkan nilai $\mathrm{Z}=-3.054(\mathrm{p}<0.0 \mathrm{I})$. Hal ini menunjukkan bahwa terdapat perbedaan skor sikap yang signifikan pada kelompok eksperimen dibandingkan dengan kelompok kontrol. Perbedaan skor sikap yang signifikan pada kelompok yang mendapat pelatihan dibandingkan kelompok yang tidak mendapatkan pelatihan.

Analisis lebih lanjut digunakan untuk melihat perbedaan skor sikap pada kelompok eksperimen sebelum dan sesudah diberikan pelatihan. Analisis statistik yang digunakan untuk menguji perbedaan skor pada kelompok yang sama adalah Wilcoxon Signed Rank. Berdasarkan hasil analisis, rerata skor sikap kelompok eksperimen pada saat pretest sebesar 64,00 ( $\mathrm{SD}=4,243)$, mengalami peningkatan menjadi 73,73 $(\mathrm{SD}=5,605)$ pada saat postest. Pengujian statistik Wilcoxon Signed Rank pada kelompok eksperimen ini menghasilkan nilai $\mathrm{Z}=-2.524(\mathrm{p}<0.05)$. Hal ini menunjukkan bahwa terdapat perbedaan skor sikap yang signifikan pada kelompok kontrol sebelum dan sesudah pelatihan.

Sementara itu, hasil analisis skor sikap terhadap kelompok kontrol menghasilkan rerata sebesar 66.00 $(\mathrm{SD}=4.055)$ pada pretest dan rerata sebesar 67.90 ( $\mathrm{SD}=4 . \mathrm{I} 49)$ pada saat postest. Uji statistik Wilcoxon Signed Rank menunjukkan nilai $Z=-2 . \mathrm{I} I 3(\mathrm{p}<0,05)$. Hal ini menunjukkan bahwa terdapat perbedaan skor sikap yang signifikan pada kelompok kontrol pada saat pretest dan postest.

\section{Skor Sikap terhadap Pendidikan Inklusif}

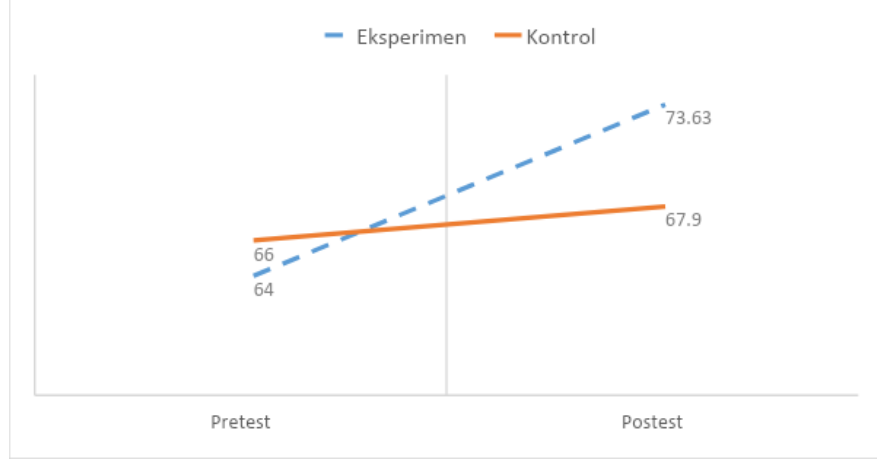

Gambar I. Skor Sikap Kelompok Eksperimen dan Kelompok Kontrol

Berdasarkan analisis diatas, dapat diketahui bahwa perubahan skor sikap terjadi secara signifikan pada kedua kelompok. Meskipun keduanya mengalami peningkatan, namun rerata skor yang dihasilkan kelompok eksperimen lebih tinggi dibandingkan kelompok kontrol. Hal ini dibuktikan pula oleh hasil uji beda Mann Withney U-Test $(\mathrm{Z}=-3.054(\mathrm{p}<0.0 \mathrm{I})$ yang menunjukkan bahwa peningkatan yang dialami oleh kelompok eksperimen sangat signifikan jika dibandingkan dengan kelompok kontrol. Hal ini menunjukkan bahwa 
hipotesis penelitian diterima, yaitu pelatihan yang menggunakan modul "Kelasku Tanpa Batas" dapat mengubah sikap guru terhadap pendidikan inklusif, dimana sikap guru yang mendapatkan pelatihan lebih positif dibandingkan sikap guru yang tidak mendapatkan pelatihan.

\section{Pembahasan}

Berdasarkan tujuan penelitian untuk melakukan validasi modul “Kelasku Menyatu Tanpa Batas” untuk mengubah sikap guru terhadap pendidikan inklusif, maka serangkaian kegiatan telah dilakukan untuk menguji validitas modul beserta perangkat alat ukur didalamnya. Dengan menggunakan metode quasi eksperimental dan desain penelitian Untreated control group design with pretest and postest, maka perlakuan hanya diberikan kepada kelompok eksperimen saja, sementara kelompok kontrol tidak diberi perlakuan apapun. Hasil penelitian mendukung hipotesis bahwa pelatihan "Kelasku Menyatu Tanpa Batas" dapat mengubah sikap guru terhadap pendidikan inklusif agar menjadi lebih positif $(Z=-3.054 ; p<0.0 I)$. Hasil temuan ini mendukung penelitian-penelitian sebelumnya yang menyatakan bahwa guru yang diberi pelatihan akan dapat menunjukkan sikap yang positif terhadap pendidikan inklusif (Avradimis, 20II; Forlin, 2008; Hassanein, 20I5; Kim (20II) Sharma, 20I2).

Meskipun kelompok eksperimen mengalami perubahan skor sikap yang signifikan setelah diberi pelatihan "Kelasku Menyatu Tanpa Batas", namun ternyata perubahan yang signifikan pun dialami oleh kelompok kontrol. Terdapat faktor yang menjadi extraneous variable yang tidak dapat dikontrol oleh peneliti dan sekaligus menjadi kelemahan dalam penelitian ini, yaitu adanya pelatihan lain yang diberikan kepada beberapa orang guru dari kelompok kontrol, dan jarak waktu antara pemberian pretest dan postest.

Pelatihan Peningkatan Kualitas Mengajar Guru oleh Dinas Pendidikan Kota Yogyakarta kepada beberapa guru di kelompok kontrol disinyalir menjadi penyebab meningkatnya skor sikap guru terhadap pendidikan inklusif karena terdapat beberapa komponen pengajaran yang sejalan dengan isi materi pelatihan "Kelasku Menyatu Tanpa Batas" yang terdapat pada sesi 4 dan 5, yaitu terkait pemahaman tentang ABK dan bagaimana seharusnya proses mengajar di kelas ABK. Selain itu, jarak waktu selama 3 minggu antara pretest dan postest kelompok kontrol menjadi salah satu faktor yang dapat mempengaruhi sikap seorang guru karena beberapa hal, yaitu (I) pengalaman kontak dengan siswa disabilitas dapat mempengaruhi sikap seseorang terhadap pendidikan inklusif (Barr \& Bracchitta, 20I5)), dimana dalam jarak waktu tiga minggu, dimungkinkan terjadi pengalaman positif antara guru dan siswa disabilitas di kelas; (2) kampanye peduli disabilitas sedang sangat marak dibagikan di media sosial, yang memungkinkan terjadi perubahan pada sikap guru terhadap pendidikan inklusif. Namun demikian, bagaimanapun skor sikap pada kelompok yang diberi pelatihan "Kelasku Menyatu Tanpa Batas" tetap mengalami peningkatan yang signifikan.

Hal yang cukup menarik dalam temuan penelitian ini adalah modul "Kelasku Menyatu Tanpa Batas" mampu untuk meningkatkan komponen afektif (sentiment) $(Z=-2.3 \mathrm{I} ; ; \mathrm{p}<0,05)$ dan konatif (concern) dari sikap $(Z=-2,205 ; p<0,05)$, namun tidak dapat secara signifikan meningkatkan komponen kognitif (attitude) dari sikap terhadap pendidikan inklusif $(Z=-I, 479 ; p>0,05)$. Terdapat inkonsistensi komponen sikap yang terjadi pada subjek terkait evaluasinya terhadap pendidikan inklusif. Interaksi dengan siswa ABK dan juga konsekuensi mengajar siswa ABK di kelas cenderung dievaluasi secara lebih positif oleh subjek setelah pelatihan, sementara ide untuk menggabungkan siswa disabilitas dan siswa reguler dalam satu kelas masih dievaluasi secara netral, tidak berubah secara signifikan walau telah diberi pelatihan. Hal ini menunjukkan bahwa pelatihan dapat membantu subjek merasa senang/nyaman dalam berinteraksi dengan siswa ABK dan cenderung lebih bersedia untuk mengajar siswa ABK di kelasnya, namun pelatihan tidak dapat membuat subjek untuk meyakini bahwa sistem penggabungan antara siswa $A B K$ dan siswa reguler dalam satu kelas merupakan sesuatu yang baik. Inkonsistensi komponen sikap ini sangat mungkin terjadi dalam diri seseorang, dimana konflik ini akan menggugah seseorang untuk terus mencari pemahaman sehingga setiap komponen kembali menjadi konsisten (Azwar, 2015). 
Ketidakmampuan pelatihan untuk mengubah evaluasi kognitif subjek berkaitan dengan rancangan kegiatan dalam sesi pelatihan. Evaluasi kognitif terhadap pendidikan inklusif berkaitan dengan evaluasi terhadap kemampuan guru dalam menghadapi siswa disabilitas di kelas (Samms, 2017). Guru perlu diberi kesempatan untuk mengalami pengajaran inklusif yang sukses sehingga merasa mampu untuk menangani beragam masalah siswa sehingga memiliki pandangan yang lebih positif terhadap inklusi (Brady \& Wolfson, 2009). Sementara itu dalam pelatihan ini, guru tidak diberi kesempatan untuk mengimplementasikan hasil pelatihan ke dalam proses belajar di kelas sehingga guru tidak yakin dengan kemampuannya sehingga keyakinannya terkait penggabungan siswa tidak berubah meski pelatihan telah diberikan. Hal ini pun menjadi kelemahan dalam penelitian ini. Sebaiknya, kegiatan refleksi terhadap pendidikan inklusif itu dilakukan bersamaan dengan pengembangan keterampilan praktis guru untuk mengedukasi siswa dengan berbagai kemampuan, karena hal akan mengarahkan pada sikap yang lebih positif terhadap pendidikan inklusif(Cologon, 20II).

Selain hal diatas, faktor dukungan dari lembaga pemerintahan pun menjadi hal yang mempengaruhi tidak signifikannya perubahan dalam komponen ini (Azwar, 20I5). Subjek mengalami disonansi kognitif karena di satu sisi pemerintah mengusulkan sistem pendidikan inklusif namun di sisi lain pemerintah juga sangat menekan guru untuk membuat siswa mendapatkan nilai yang tinggi pada Ujian Nasional. Tidak adanya dukungan yang kuat dari pemerintah membuat subjek merasa ragu dengan sistem penggabungan siswa disabilitas di kelas reguler karena akan membuatnya sulit mencapai target pemerintah dalam Ujian Nasional.

Terdapat keterbatasan dalam penelitian ini, diantaranya adalah desain penelitian quasi eksperimental menyebabkan banyak hal yang tidak dapat dikontrol dalam penelitian, salah satunya adalah faktor histori yang sangat memungkinkan bahwa peningkatan kemampuan yang terjadi pada subjek tidaklah semata-mata dikarenakan perlakuan yang diberikan, melainkan karena faktor lain, diantaranya adalah (I) Workshop dari Dinas Pendidikan; (2) Paparan media sosial; (3) waktu pemberian pretest dan post-test; (4) rancangan kegiatan refleksi yang tidak mengintegrasikan dengan aplikasi mengajar; dan (4) ketidaksetaraan pemilihan subjek juga menjadi salah satu penyebab tercemarnya hasil penelitian, dimana tidak dibatasi pengalaman mengajar dengan jumlah siswa ABK dalam satu kelas beserta tingkat keparahannya.

\section{Penutup}

Hasil analisis data penelitian menunjukkan bahwa modul "Kelasku Menyatu Tanpa Batas" teruji valid secara konten maupun empiris dalam mengubah sikap guru terhadap pendidikan inklusif. Bagi peneliti selanjutnya, diharapkan melakukan beberapa hal berikut ini, yaitu: (I) dapat mengembangkan modul "Kelasku Menyatu Tanpa Batas” dengan estimasi waktu yang lebih panjang disertai dengan desain kegiatan yang memungkinkan peserta untuk mengimplementasikan hasil pelatihan dalam praktik langsung dikelas beserta pemantauan hasil; (2) Peneliti diharapkan dapat lebih memperhatikan kesetaraan karakteristik subjek pada saat melakukan pemilihan, terutama pada jumlah siswa ABK dan tingkat keparahannya dalam satu kelas; (3) Peneliti sebaiknya memperhatikan waktu pemberian pretest dan postest sehingga extraneous variable lebih dapat dikendalikan; dan (4) Peneliti sebaiknya melakukan follow-up untuk mengetahui sejauh mana perubahan sikap menetap pada subjek penelitian.

\section{Daftar Pustaka}

Albarrin, D. \& Mcnatt, P. S. (2005). Maintenance and Decay of Past Behavior Influences: Anchoring Attitudes on Beliefs Following Inconsistent Actions, Personality and Social Psychology Bulletin, 3I(6): 719-733. doi:I0.II77/0I46I67204272I80. 
Antara News. (2016). Yogyakarta kuatkan komitmen wujudkan kota inklusi. Diakses melalui http://jogja.antaranews.com/berita/343383/yogyakarta-kuatkan-komitmenwujudkan-kota-inklusi pada tanggal 4 Januari 2017 pukul I I:03 WIB.

Azwar, S. (2015). Sikap Manusia: Teori dan Pengukurannya. Yogyakarta: Pustaka Pelajar.

Anderson, C.J.K., Klassen, R. M., \& Georgiou, G.K. (2007). What Teachers Say They Needs and What School Psychologists Can Offer. School Psychology International, 8 (2): I3I-I47, doi: I0.II77/0I4303430707808.

Baker-Ericzén, M. J., Mueggenborg, M. G., \& Shea, M. M. (2009). Impact of trainings on child care providers' attitudes and perceived competence toward inclusion: What factors are associated with change? . Topics in Early Childhood Special Education, 28(4), 196-208.

Barr, J.J. \& Bracchitta, K. (20I5). Attitudes Toward Individuals with Disabilities: The Effects of Contact with Different Disability Types. Current Psychology, 34, 223-238, doi: I0.I007/sI2I44-0I4-9253-2.

Beckett, A. E., (2009) 'Challenging disabling attitudes, building an inclusive society': considering the role of education in encouraging non- disabled children to develop positive attitudes towards disabled people, British Journal of Sociology of Education, 30(3), 317-329, doi: I0.1080/0I425690902812596.

Booth, T. (20II). The name of the rose: Inclusive values into action in teacher education, Prospects, 4I, 303318, doi: I0.1007/sII I25-0I I-9200-z.

Booth, T., \& Ainscow, M. (20II). Index for inclusion: developing learning and participation in schools. Bristol: Center for Studies Inclusive Education.

Connor, D., \& Ferri, B. (2007). The conflict within: Resistance to inclusion and other paradoxes in special education, Disability \& Society, 22, 63-77.

Crisp, R. (2010). The Psychology of Social and Cultural Diversity; Social Issues and Interventions. London: Wiley-Blackwell.

deBoer, A., Pijl, S. J. \& Minnaert, A. (20II). Regular primary school teachers' attitudes towards inclusive education: a review of the literature, International Journal of Inclusive Education, I5 (3), 33 I-353, doi: I0.1080/I3603II0903030089.

Dukmak, S. (2013). Regular Classroom Teachers' Attitudes towards Including Students with Disabilities in the Regular Classroom in the United Arab Emirates. The Journal of Human Resource and Adult Learning, 9 (I) 26-40.

Falvey, M.A. \& Givner, C.C. (2005). What is an Inclusive School? Dalam Thomas, J., Carley, S. \& King, P. (eds). Alexandria: Association for School and Curriculum Development.

Fishbein, M. \& Ajzen, I. (1975). Belief, attitude, intention, and behavior: An introduction to theory and research. Reading, MA: Addison-Wesley.

Forlin, C., Earle, C., Loreman, T., \& Sharma, U. (20II). The Sentiments, Attitudes, and Concerns about Inclusive Education Revised (SACIE-R) Scale for Measuring Pre-Service Teachers' Perceptions about Inclusion. Exceptionality Education International, 2I(3), 50-65.

Forlin, C., Loreman, T., Sharma, U. \& Earle, C. (2009). Demographic differences in changing pre- service teachers' attitudes, sentiments and concerns about inclusive education, International Journal of Inclusive Education, 13(2), 195-209.

Grenier, M. (2010). Moving to inclusion: a socio-cultural analysis practice. International Journal of Inclusive Education, I4(4), 387-400. doi: I0.1080/I3603II0802504598. 
Haifani, A. (20II). Pengaruh pelatihan "guru peduli anak berkebutuhan khusus (ABK)" pada pengetahuan dan sikap penerimaan guru terhadap Anak Berkebutuhan Khusus di Sekolah Dasar Inklusi. Tesis. Fakultas Psikologi Universitas Gadjah Mada. Tidak Diterbitkan.

Hassanein, E.E. (2015) Changing Teachers' Negative Attitudes Toward Persons With Intellectual Disabilities. Behavior Modification, 39 (3), 367-389, doi: I0.I I77/0I454455I4559929.

Hanjarwati, A. \& Aminah, S. (20I4). Evaluasi implementasi kebijakan pemerintah kota Yogyakarta mengenai pendidikan inklusi. Inklusi, I(2), 22I-248.

Ishartiwi (2010). Implementasi pendidikan inklusif bagi Anak Berkebutuhan Khusus dan sistem pendidikan nasional (SPN). Jurnal Pendidikan Khusus, 6(2), I-9.

Jordan A, Glenn C, \& McGhie-Richmond D (2010) The SET project: Effective teaching and its relationship to teachers' epistemological beliefs and inclusive teaching practices. Teaching and Teacher Education, 26: $259-266$.

Jordan, A., Schwartz, E., \& McGhie-Richmond, D. (2009). Preparing teachers for inclusive classrooms. Teaching and Teacher Education, 25(4), 535-542. doi:I0.1016/j.tate.2009.02.010.

Kim, J. (20II). Influence of teacher preparation programmes on preservice teachers' attitudes toward inclusion, International Journal of Inclusive Education, I5(3), 355-377, doi: I0.1080/I3603II0903030097.

Kurniawati, F., deBoer, A.A.,, Minnaert, A. E. M.G., \& Mangunsong, F. (20I4). Characteristics of primary teacher training programmes on inclusion: a literature focus, Educational Research, 56 (3), 310-326, doi: I0.I080/00I3I88I.20I4.934555.

Kurniawati, F. deBoer, A. A., Minnaert, A. E. M. G., \& Mangunsong, F. (2016). Evaluating the effect of a teacher training programme on the primary teachers' attitudes, knowledge and teaching strategies regarding special educational needs, Educational Psychology, 53 (4), I3-2I, doi: I0.1080/0I4434I0.20I6.II76I25.

Lindsay, G. (2007). Educational psychology and the effectiveness of inclusive education/ mainstreaming. British Psychological Society, 77, I-24.

Loja, E., Costa, M. E., Hughes B., \& Menezes, I. (2013). Disability, embodiment and ableism: stories of resistance. Disability \& Society, 28(2), 190-203.

Lubis, E. N. (2016). Implementasi kebijakan penyelenggaraan pendidikan inklusif jenjang SD se-kota yogyakarta. Jumnal Kebijakan Pendidikan, 2(5), I49-I60.

Loreman, T., \& Earle, C. (2007). The development of attitudes, sentiments, and concerns about inclusive education in a content-infused Canadian teacher preparation program. Exceptionality Education Canada, I7(I), 85-106. Retrieved from http://ejournals.library.ualberta.ca/index.php/eei pada tanggal 5 Januari 2017 pukul I3: 3 I WIB.

Mezirow, J. (1997). Transformative Learning: Theory to Practice. New Directions For Adult And Continuing Education, 74, II2- I2I.

Pijl, S. J. (2010). Preparing teachers for inclusive education: some reflections from the Netherlands, Journal of Research in Special Educational Needs, IO(I),I97-20I, doi: I0.I I I /j.I47I-3802.2010.01 I65.x

Pemerintah Kota Yogyakarta. Peraturan Walikota Yogyakarta Nomor 47 Tahun 2008 tentang Penyelenggaraan Pendidikan Inklusi di Kota Yogyakarta. Diakses melalui 
http://hukum.jogjakota.go.id/data/Perwal\%2047\%20th\%202008.pdf pada tanggal 22 Oktober 2016 pukul I0:36 WIB.

Pemerintah Provinsi Daerah Istimewa Yogyakarta. Peraturan Gubernur Daerah Istimewa Yogyakarta Nomor 4I Tahun 2013 Tentang Pusat Sumber Pendidikan Inklusif Dengan Rahmat Tuhan Yang Maha Esa. Diakses melalui http://bappeda.jogjaprov.go.id/download/download/250 pada tanggal I5 November $20 \mathrm{I} 6$ pukul I3.30 WIB.

Savage R. S., \& Erten, O. (2015). Teaching in Inclusive Classrooms: The Link Between Teachers' AttitudesPractices and Student Outcomes. Journal of Psychology and Psychotherapy, 5, 219-228. doi:I0.4I72/216I-0487.10002I9.

Shadish, W.R., Cook, T., \& Campbell, D. (2002). Experimental and quasi-experimental designs for general causal inference. Boston: Houghton Mifflin Company.

Sharma, U. (20II). Changing heart, head, and hands of teachers to teach in inclusive classroom: why and how?. Bangladesh Education Journal, IO(2), 7-I8.

Sharma, U. (2012). Changing Pre-Service Teachers' Beliefs to Teach in Inclusive Classrooms in Victoria, Australia. Australian Journal of Teacher Education, 37(IO), 53-66.

Tarnoto, N. (20I4). Permasalahan-permasalahan yang dihadapi oleh sekolah penyelenggara inklusi pada tingkat sekolah dasar. Humanitas, I3(I), 20-6I.

Taylor, E. W. (2007). An update of transformative learning theory: a critical review of the empirical research (1999-2005). International Journal of Lifelong Education, 26(2), I73-191, doi: I0.1080/0260137070I2I9475.

Woolfson, L. M., \& Brady, K. (2009). An investigation of factors impacting on mainstream teachers' beliefs about teaching students with learning difficulties. Educational Psychology, 29(2), 22I-238. doi:I0.I080/0I4434I0802708895. 